\title{
A new genus and species of trigoniuline milliped from Western Australia (Spirobolida: Pachybolidae: Trigoniulinae)
}

\author{
Richard L. Hoffman \\ Virginia Museum of Natural History \\ Martinsville, Virginia 24112, USA
}

\begin{abstract}
A new genus and species, Austrostrophus stictopygus, is described from northern Western Australia. The presence of punctate paraprocts, very rare in spiroboloid diplopods, is shared with Ainigmabolus chisholmi of New South Wales, but apparently only as a homoplasic condition.
\end{abstract}

\section{INTRODUCTION}

Whether considered a subfamily of the Pachybolidae or a discrete family, trigoniuline millipeds comprise a conspicuous element in the fauna of southeastern Asia and Indonesia, whence some 21 genera are currently recognized (Jeekel, 2001). The group is, however, only marginally represented in Australia, chiefly by Zygostrophus and Ainigmabolus on the eastern edge of the continent, and the recently described Speleostrophus (Hoffman, 1994) from an island on the west coast. The recent discovery of a highly disjunct new trigoniuline from Western Australia suggests that undercollecting along the western and northern periphery of the continent may account for this apparent poverty of Australian spiroboloids.

\section{Family Pachybolidae Cook}

\section{Subfamily Trigoniulinae Attems}

\section{Austrostrophus gen nov}

\section{Type species}

Austrostrophus stictopygus sp. nov.

\section{Diagnosis}

A trigoniuline genus characterized by the enlarged, distally excavate, gonopod coxae, into which the elongated, slender telopodites are basally recurved. Submarginal belt of paraprocts conspicuously set with large coarse punctures. Posterior edge of metazona with specialized fringe composed of small denticulate projections.

\section{Distribution}

Western Australia.

\section{Etymology}

A masculine neologism composed of the elements austro (from Latin australis, in allusion to the country of origin) + -strophus, a combining form employed in many generic names in this subfamily.

\section{Austrostrophus stictopygus sp. nov.} Figures 1-10

\section{Material examined}

Male holotype (WAM T46241), from Western Australia: Burrup Peninsula, Rocky Hill at Hearson Cove (20 37'06"S, $\left.116^{\circ} 47^{\prime} 05^{\prime} \mathrm{E}\right)$, R. Teale leg. 22 May 2002. Two immature females (WAM T46956) from the same locality, 30 September 2002, R. Teale and M. Maier, leg.

\section{Diagnosis}

With the characters of the genus.

\section{Holotype}

Adult male, length approximately $52 \mathrm{~mm}$ (broken), maximum diameter $4.2 \mathrm{~mm}$. 51 segments + telson. Colour of recently preserved specimen: prozona grayish, mesozona piceous to black, metazona orange-brown. Mesozonal black pattern narrowed ventrad and absent above leg bases; antennae, legs, sterna and pleural region similar in colour to metazona.

Head without modifications, sides of genae slightly convex but convergent ventrad interantennal and interocellarial widths $1.2 \mathrm{~mm}$, ocellaria subrounded, maximum length $0.5 \mathrm{~mm}$, about 36 ocelli in rows (4-5-7-6-6-5-3). 7+7 labral setae, $2+2$ clypeal setae, those of each side widely separated. Antennae short, $2^{\text {nd }}$ and $6^{\text {th }}$ articles longest, similar in size and shape, 3rd-5th shorter and slightly more triangular in outline; outer distal ends of $5^{\text {th }}$ and $6^{\text {th }}$ articles with rounded, slightly convex sensory area, depigmented and appearing semimembranous; $7^{\text {th }}$ article very short, with four terminal sensory cones. Mentum of 


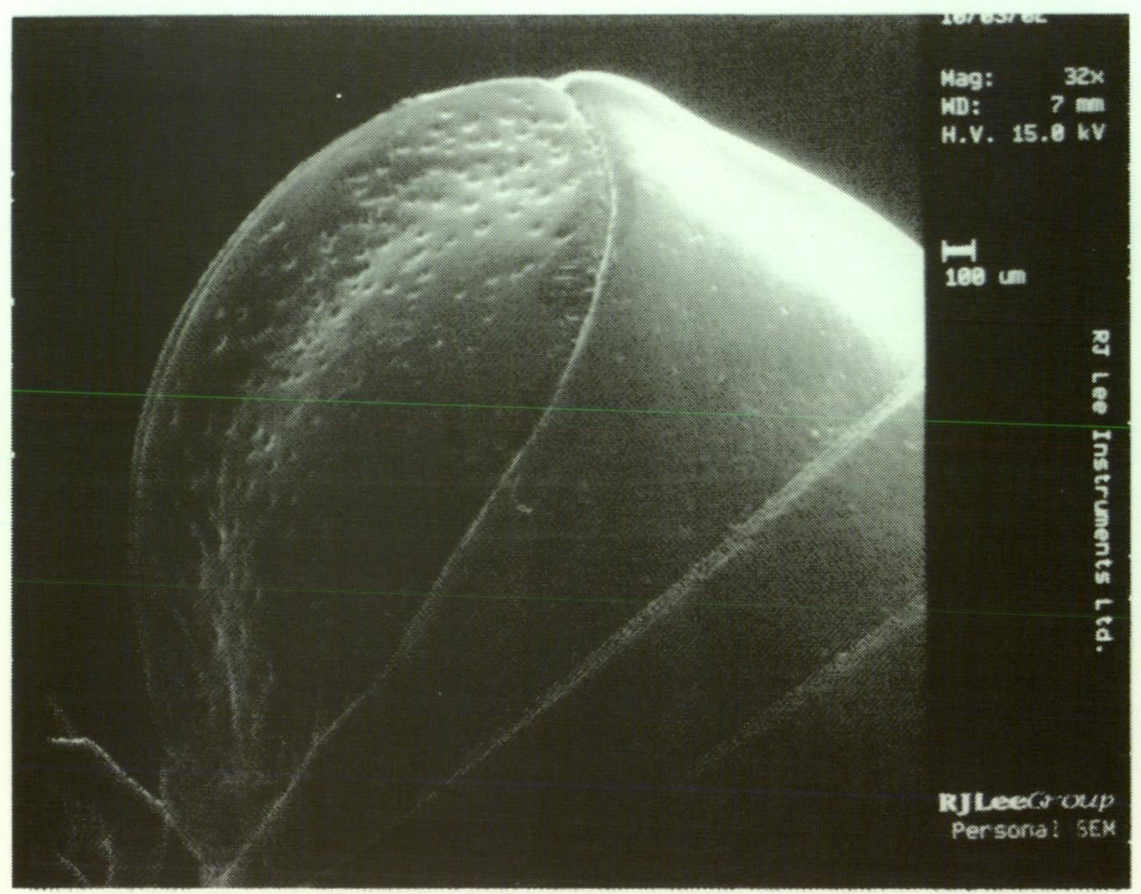

Figure 1 Posterior end of body, showing abbreviated form of the epiproct and coarsely punctate condition of the paraprocts (SEM x32).

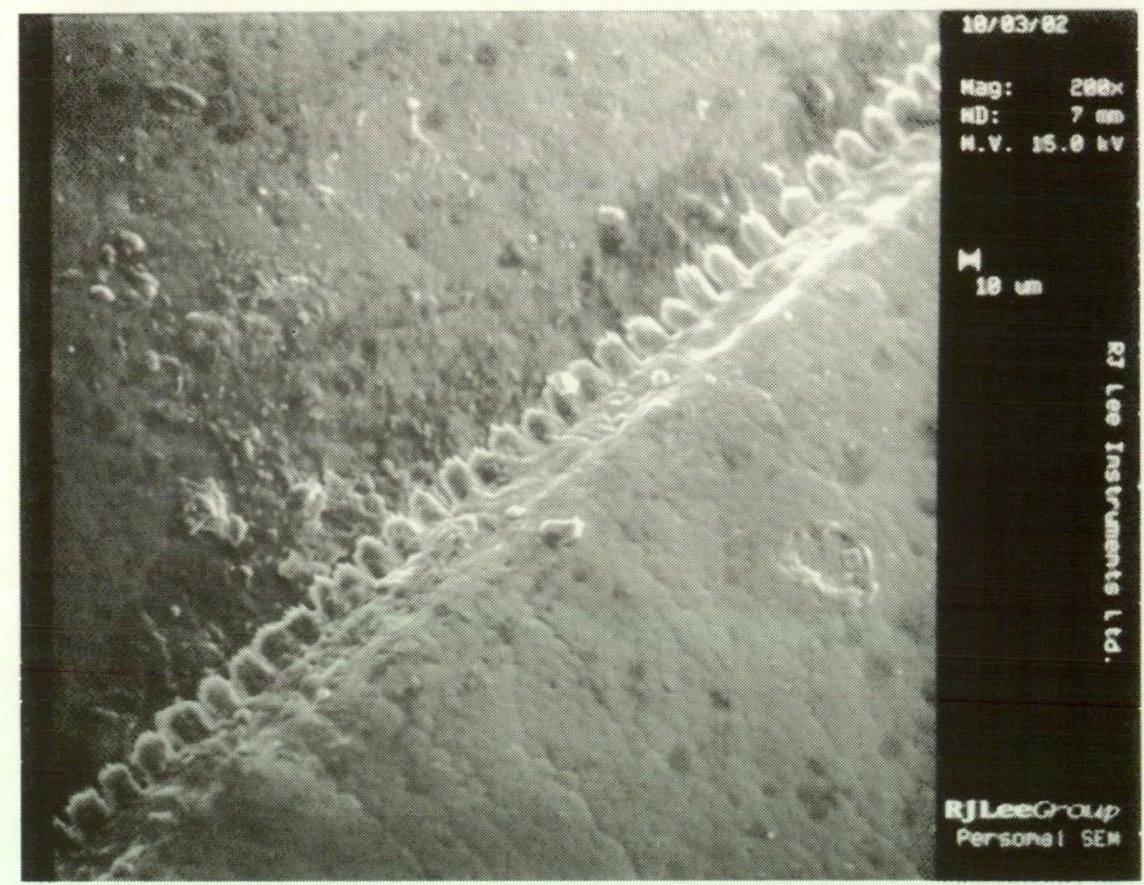

Figure 2 Posterior edge of metazonum showing the palaeate fringe (SEM x200).

gnathochilarium with low but distinct median ridge, prebasilar sclerite very thin. Mandibular bases without lobes or other modification.

Lateral ends of collum subtriangular as usual in this family; pleural region of $2^{\text {nd }}$ segment produced ventrad and visible beneath end of collum as a digitiform lobe. Surface of collum and all body segments superficially smooth and polished: with magnification (60X) surface texture is a uniform isodiameteric mesh, on which is superimposed a pattern of longitudinal striations; prozona with several concentric striations below level of ozopores, curved posteriad at their ventral ends. Pores prominent, located in mesozona below level of lateral suture. Pleurotergal suture line visible; sterna subquadrate, smooth (Figure 4). Metazona slightly elevated above level of mesozona, and caudally decurved slightly, becoming much thinner and edged with a fringe composed of small separate, denticulate units (paleae) (Figures 2, 3). 

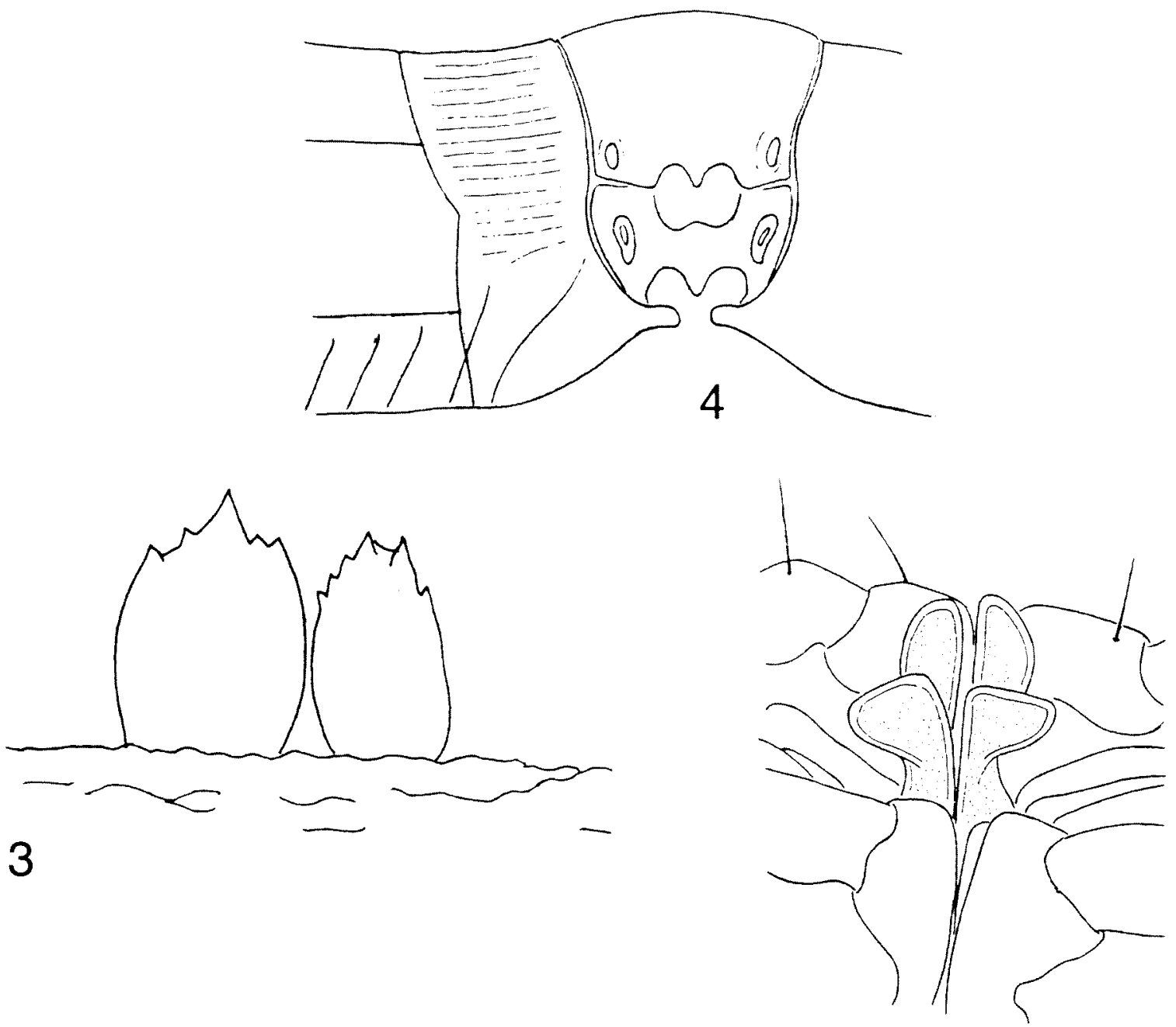

Figures 3-5 3. Two individual paleae, greatly enlarged (freehand, about $2000 \mathrm{x}$ ). 4. Sternal region of midbody segment, legs removed to show coxal sockets and partial closure of posterior sockets. 5. Bases of leg pairs 2-6, showing form of processes of $3^{\text {rd }}$ and $4^{\text {th }}$ coxae, posterior aspect.

Terminal segment (Figure 1) not produced dorsomedially; most of paraprocts visible in dorsal aspect, their posterior edge set off by a moderately deep, broad groove beset with numerous large coarse punctures, disk of paraprocts impunctate or nearly so. Hypoproct transversely narrow, unmodified.

Posterior coxal cavities partially closed by small median projection of sterna (Figure 4). Legs relatively long, tarsi visible in dorsal aspect when extended; length ratio of podomeres in descending order: 2-3-6-4-5-1. Podomeres essentially glabrous, basal four with a single small seta at distal end ventrally, postfemur with a distinctly larger seta in that position, tarsi typically with three large setae (nearly length of tarsal claw) in a ventrodistal row, and a single large supra-apical seta. Anterior legs without pads, although ventral surface of apical podomeres appears depigmented and less sclerotized than dorsal surface (perhaps endowed with moderate holding ability). Tarsal claws similar in size and shape to those of other legs. Coxae of legs 3 and 4 produced into conspicuous, flattened lobes, those of $4^{\text {th }}$ coxa turned laterad apically (Figure 5).

Anterior gonopods distinctive in the globosely enlarged coxae, deeply excavate on mesal side, accommodating basal half of telopodites, anterior surface of coxae not produced into slender apices (Figure 6). Sternum modified " $Y$ " shape, prolonged slightly behind coxae, sternal apodeme reflexed caudad and not visible in anterior aspect; posterior extension of sternum separated as a discrete elongate sclerite, narrowed at each end, and in contact with basal end of telopodite (Figure 8, PXS). Telopodite differing from typical trigoniuline structure in being attached to an elevated posterior rim of the coxa, then abruptly recurved into cavity of the latter, distal half reflexed ventrad behind median sternal projection as a slender stalk, apically 

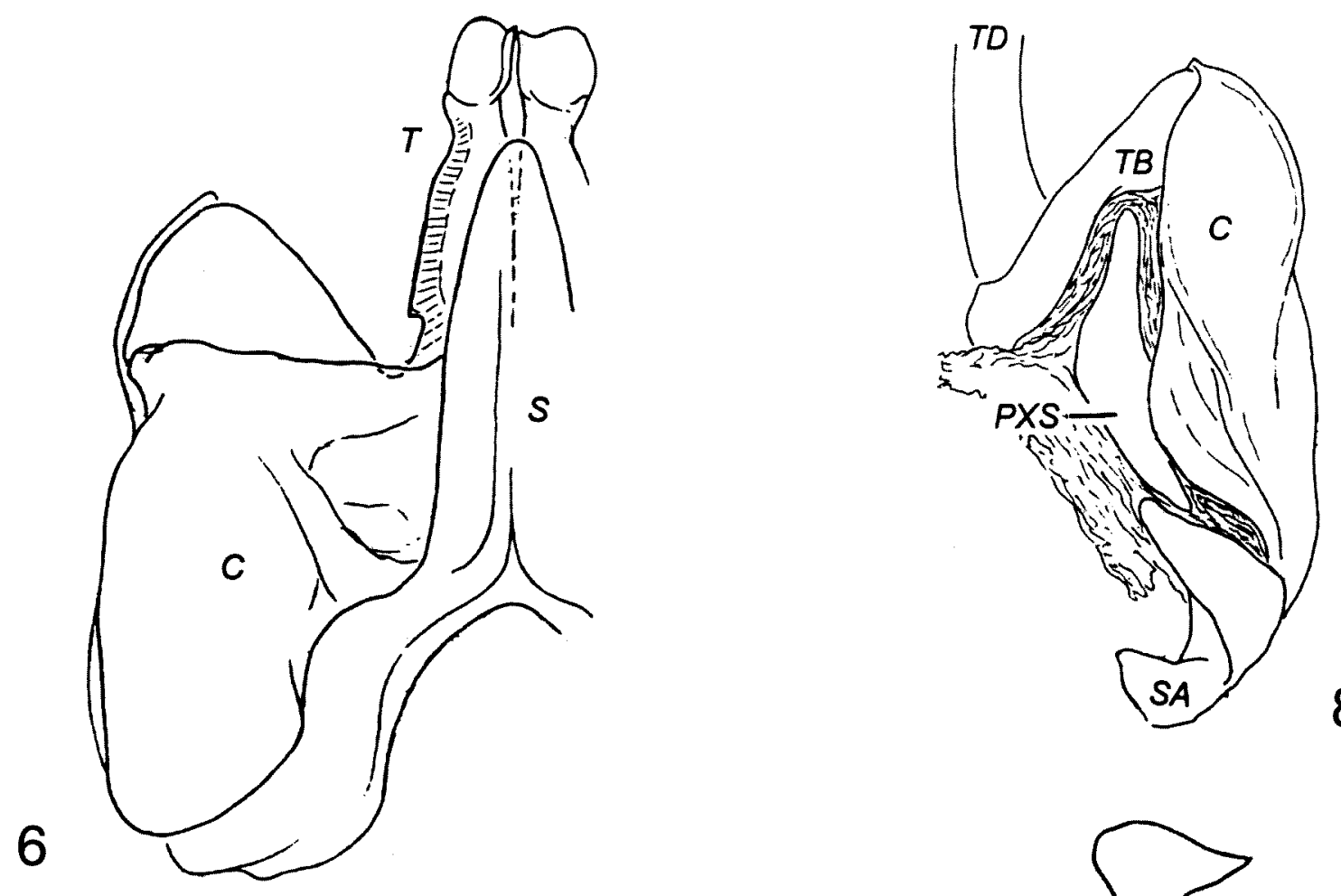

8

Figures 6-8 6. Left side of anterior gonopods, anterior aspect. S, sternum, C, coxa, T, telopodite. 7. Lateral aspect of gonopods (posterior pair concealed) with prostatic gland (stippled, at left) and retractor muscles of telopodite indicated by broken lines inside coxa. 8. Posterior view of left anterior gonopod, showing prolongation of coxa (C), with base (TB) and distal shaft (TD) of telopodite. PXS, posterior extension of sternum; SA, reflexed sternal apodeme.

capitate just beyond apex of sternal projection (Figures 7,9).

Posterior gonopod (Figure 10) generally conforming to basic trigoniuline pattern: median sternal element $(S)$ present, merging each side into a coalesced coxosternal region containing (1) a small chamber into which the prostatic duct (PD) discharges, and (2) a small, short, digitiform projection. Distal 2/3rds of gonopod (telopodite) set off at nearly a right angle by a deep flexible articulation (A). Prostatic groove courses on medial side to a clear membranous subapical lappet; form of telopodite and its various lobes and processes as shown in Figure 10. 


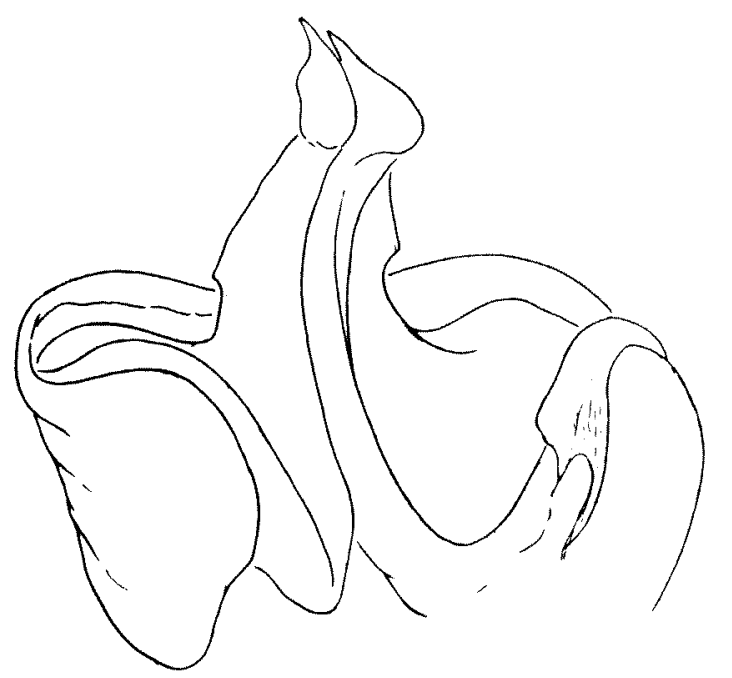

Figure 9 Oblique posteromedian aspect of gonopods to show the prominent flexure of the telopodites into the distal coxal cavity unique to this genus.

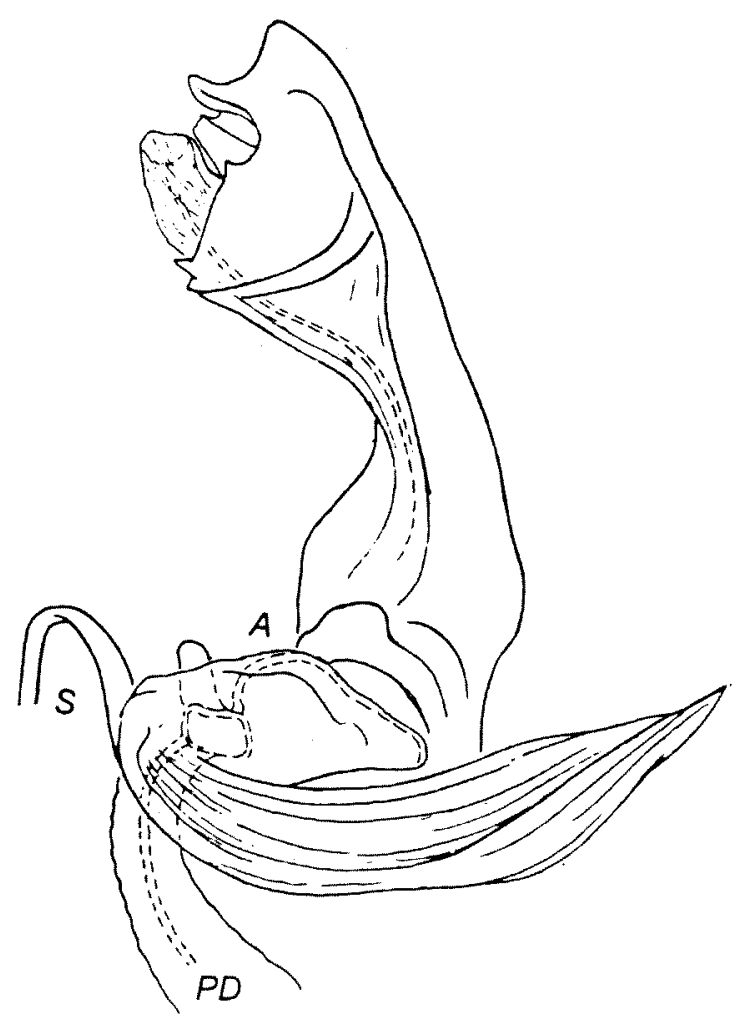

Figure 10 Posterior gonopod, lateral aspect, sternal apodeme concealed by the protractor and retractor muscles. PD, prostatic duct with its sclerotized internal tube. S, sternum; $A$, flexible articulation between coxal and telopodital regions.

\section{Etymology}

From the Greek stiktos (punctured) + pygos (rump), in allusion to the coarsely punctate paraprocts.

\section{COMMENTS}

\section{Punctate paraprocts}

My initial impression, confirmed by a preliminary literature survey and survey of material at hand, was that this character was not known for the entire order Spirobolida. Only through serendipity did I notice the remark by Verhoeff (1937: 149) that in Ainigmabolus chisholmi the "Analklappen neben dem innenrande mit mehreren, unregelmassigen Eindrücken." This species, a trigoniuline from New South Wales, shows virtually no similarities in gonopod structure with $A$. stictopygus, and apparently the paraproct modification must be considered a "geographic homoplasy" peculiar to Australia rather than any kind of synapomorphy for the two taxa.

\section{Metazonal fringe}

In many orders of Diplopoda the posterior edge of the metazona is provided with a thin, transparent, sclerotized membrane ("limbus"), variable both in width and ornamentation of its edge. The definitive treatment of limbus occurrence throughout helminthomorph Diplopoda (Schmidt, 1962), recorded that in the three "trigoniuline" families (Pachybolidae, Trigoniulidae, Spiromimidae) "ein eigenlicher Limbus ist auch hier nicht vorhanden" - at least in species of the six genera examined. In one, Trigoniulus ceramicus, the edge of the metazona itself is irregularly indented and darkly pigmented, but the typical limbus structure of a clear membrane with modified edge is in no way approximated. The condition in Austrostrophus is perhaps an elaboration of this simple form. The margin of the metazona is notably thinner than the sclerite otherwise, but is opaque and pigmented, no clear membrane is present, and the scale-like individual units (for which the term paleae is suggested, singular palea) of the fringe originate separately from the edge itself. Perhaps this expression could be distinguished by the name "paleate". In those taxa in which a true limbus is well-developed, e.g., Odontopygidae, the hyaline membrane itself can usually be removed intact as a continuous clear strip. In a general way, the true limbus seems to be best developed in taxa in which other character systems are clearly derived, and therefore indicative of an evolutionarily advanced status for such groups.

\section{Gonopods}

Although it seems generally appreciated that the 
sperm transfer process in most helminthomorph diplopods is facilitated by a what is regarded as a prostatic secretion (with ?enzymatic, ?nutritive, ?buffering function) the glands themselves have not received a thorough comparative study. In Polydesmida, they lie in the coelom of segment 7 (often adjacent segments as well) and their secretion is conducted through the gonocoxae to a prostatic groove originating at the base of the telopodite. In Spirostreptida, the glands are generally located on the posterior side of and in close proximity to the gonocoxal folds. They have been scarcely noticed in Spirobolida, but their sclerotized ducts entering the bases of posterior gonopods are frequently illustrated. Because of the excellent state of preservation of the holotype of $A$. stictopygus I was able to determine that the glands are located in the $8^{\text {th }}$ segment well behind the bases of the gonopods and each is nearly as large as the preceding gonocoxa (Figure 7). A long duct connects to the coxosternal region, the central sclerotized tube surrounded by a thick layer of what appears to be additional glandular tissue (Figure 10).

The function of the small internal chamber (Spermagrube of Verhoeff, 1937, Figure 13) remains unknown; it appears too small to be an effective reservoir. Some trigoniuline genera are credited with the presence of two such chambers.

Figure 8 shows the unique formation of the anterior gonocoxa in this genus. The posterior surface is greatly elongated distal instead of being short and basically transverse with the telopodite hinged along an exposed seam and apparently capable of very limited movement. In Austrostrophus, the base of the telopodite is only narrowly joined to the edge of the coxa, and apparently capable of being extended and retracted (Figure 7 shows retractor muscles only, I did not wish to locate the extensors by further dissection of the single specimen).

\section{Relationships}

As there remain a number of Papuasian trigoniuline genera of which the gonopod structure is unknown or only poorly known, I am unable to this time to suggest any candidate sister-group for Austrostrophus. The singular form of the anterior gonopods is not approached in any genus known to me, nor the presence of a modified metazonal edge. Curiously, the posterior gonopods offer no corresponding pecularities, and in fact these appendages tend to be conservatively quite similar through the subfamily.

\section{ACKNOWLEDGEMENTS}

I am very much indebted to my colleague Mark Harvey (WAM), who on realizing that a trigoniuline from Western Australia would be of particular interest, brought the specimen to my attention. I am much indebted to Dr. Harvey for the the opportunity to examine and describe this curious, disjunct spiroboloid, and to Patrick Brannon, VMNH technician, for the SEM photography.

\section{REFERENCES}

Jeekel, C. A. W. (2001). A bibliographic catalogue of the Spirobolida of the Oriental and Australian regions (Diplopoda). Myriapod Memoranda 4: 5-103.

Hoffman, R. L. (1994). Studies on spiroboloid millipeds. XVIII. Speleostrophus nesiotes, the first known troglobitic spiroboloid milliped, from Barrow Island, Western Australia (Diplopoda: Pachybolidae: Trigoniulinae). Myriapodologica 3: 19-24.

Schmidt, D. (1962). Über die taxionomische Wertigkeit von Strukturen des Metazonit-Hinterrandes bei Diplopoden. Senckenbergiana biologia 43: 65-80.

Verhoeff, K. W. (1937). Ueber einige neue Diplopoden aus Australien. Records of the Australian Museum 20: 133-149.

Manuscript received 11 November 2002; accepted 11 December 2002 